\title{
Grade III Spontaneous Rectus Sheath Hematoma Concomitant to SLE
}

\author{
Ayşe Şahin Tutak ${ }^{1 *}$, Hüseyin Avni Fındıklı1, Sefer Aslan", Esin Taştekin² \\ ${ }^{1}$ Department of Internal Medicine, Adıyaman University of Medical Faculty, Adıyaman, Turkey \\ ${ }^{2}$ Department of Chest Diseases, Adiyaman University of Medical Faculty, Adiyaman, Turkey
}

"Corresponding Author: Ayse Sahin Tutak, Department of Internal Medicine, Adiyaman University of Medical Faculty, Adiyaman, Turkey, Tel: +904162161015; Fax: +904162161015; E-mail: aysesahintutak@ hotmail.com

Received: 05 October 2018; Accepted: 19 October 2018; Published: 30 October 2018

\begin{abstract}
Rectus sheath hematoma is defined as the accumulation of blood within the rectus sheath caused by tears in the epigastric arteries or the rectus muscle fibres. Although seen rarely, the use of anti-coagulants has been held responsible as the most common predisposing factor in the etiology of autoimmuune diseases. Systemic lupus erythematosus (SLE) is a disease which is challenging in diagnosis and management both in respect of multiple clinical responses to the disease and various complications. Hemorrhagic markers have a place in the clinical manifestation of the disease. The case is here presented of a 78 -year old male patient who was admitted to the Intensive Care Unit (ICU) with a diagnosis of pneumonia, and during hospitalisation was diagnosed with SLE and rectus sheath hematoma. The points which can be discussed in this case are that there was no history of anticoagulant use, and despite the coagulation function test results in the normal range and the order of low-dose (40 $\mathrm{mg} /$ day) enoxiparin sodium as thromboembolism prophylaxis in the first 2 days of admittance, this is the first reported case of spontaneous giant rectus sheath hematoma where SLE was held responsible as an etiological factor.
\end{abstract}

Keywords: Rectus sheath hematoma; SLE; Hemorrhage

\section{Introduction}

SLE is a systemic disease of autoimmune origin, the cause of which is not fully known, which can involve all systems and is encountered with different clinical tables, can often be confused with other systemic diseases, and 
therefore when diagnosis is delayed can become inextricably intertwined with clinical syndromes. The clinical onset of the disease is often seen as arthritis, a subcutaneous rash, photosensitivity, immune-mediated cytopenia and renal involvement. It is seen 9-10- fold more in females than males, the majority of patients are females of child-bearing age and the mean age at onset has been reported as 30 years $[1,2]$.

Rectus sheath hematoma develops following the accumulation of blood within the rectus sheath because of tears in the epigastric arteries or the rectus muscle fibres [3]. Findings generally determined in patients are abdominal pain, abdominal mass, ecchymosis in the abdominal wall, a fall in hemolobin values, nausea, vomiting, peritoneal irritation and fever. Ultrasonography (USG), computed tomography (CT) and magnetic resonance imaging methods are used in diagnosis. Although USG is the first diagnostic option because it is inexpensive, easily available and has high rates of sensitivity, the differentiation of some intra-abdominal lesions from extra-abdominal lesions can be difficult. CT is a much superior imaging method in the evaluation of location, spread and size of the hematoma. Classification of hematoma is possible with CT $[4,5]$.

\section{Case Report}

A 78-year old male presented at the Emergency Dept with complaints of dyspnea, cough and fever. On examination, body temperature was found to be $38.2^{\circ} \mathrm{C}$, blood pressure $135 / 90 \mathrm{~mm} \mathrm{Hg}$, pulse $96 \mathrm{bpm}$ and respiratory rate 19 breaths/minute with an oxygen saturation of $87 \%$ in room air. Pulmonary radiographs taken after the respiratory system examination were evaluated as pneumonia and as the costophrenic sinus in the right lung was closed, cardiac Doppler USG examination was applied. Ejection fraction was calculated as 50\% and minimal pericardial effusion was determined, so the patient was admitted to ICU with a diagnosis of pneumonia. In the medical history of the patient, there was a diagnosis of psychotic disorder for more than 5 years, general fatigue which had been ongoing for more than 1 year, tiredness and joint pain and skin lesions that had formed on various parts of the body. The patient had no history of taking regular medication.

In the hematological examination on admittance, the following values were determined : red blood cell count (RBC): $3.4 \times 10$ (6) /microl (4.04-6.13) hemoglobin(Hb) level: $11.5 \mathrm{~g} / \mathrm{dL}$ (12-18.1), hematocrit (Htc) level: 33,5\% (35-53.7), white blood cell count (WBC) 12,000/mm (4.3-10.3), and platelet count (PIt): $170 \times 10$ (3) /microl (142424). Urinalysis revealed protein $3+$ and occult blood $3+$, leukocytes $3+$ clearance + . Blood chemistry and serological tests showed an elevated creatinine level of $2.39 \mathrm{mg} / \mathrm{dL}$, urea: $58 \mathrm{mg} / \mathrm{dl}$, C-reactive protein: $3.9 \mathrm{mg} / \mathrm{dL}$ (0-0.8), sedimentation: $52 \mathrm{mg} / \mathrm{dl}$ (2-20), activated partial thromboplastin time (aPTT) 27 seconds (26.5-40), INR 1.32 (0.9-1.2), and liver function tests were normal. There was no production in the blood culture taken and viral serology was normal. In the light of the findings of complaints of chronic fatigue, skin findings (vesiculo-bullous lesions), polyarthralgia, the history of psychosis, clearances in the urine and the telescopic appearance and pericardial effusion, it was thought that this could be a disease of autoimmune origin. Thus, autoantibody screening was applied and an elevated antinuclear antibody (ANA) positive and an anti-double-stranded (ds) DNA antibody level of $>400 \mathrm{IU} / \mathrm{mL}$ were determined. The $\mathrm{C} 3$ and C4 levels were low $(50 \mathrm{mg} / \mathrm{dl}, 11 \mathrm{mg} / \mathrm{dl}$, respectively). The $\mathrm{IgG}$, 
IgM aPL, lupus anticoagulant tests, c-anca, and p-anca were negative. A diagnosis of SLE was made for the patient and methylprednisolone treatment was started.

On the 3rd day of hospitalisation, the general appearance of the patient deteriorated, so the CBC and biochemical routines were repeated as blood pressure was $86 / 50 \mathrm{~mm} \mathrm{Hg}$, and pulse was $114 \mathrm{bpm}$. In the laboratory results, a significant decrease (26\%) was seen in hematocrit. The thrombocyte count, thrombin time and partial thromboplastin time were within normal limits. In accordance with these results, the 40mg/day enoxiparin sodium given as thromboembolism prophylaxis was stopped, hemodynamic support was provided, and as ecchymotic areas (Figure 1) developed spontaneously in the abdominopelvic region after 8 hours, emergency USG was performed and an appearance was observed which could be consistent with hematoma within the abdomen and rectus sheath. The patient was brought to a stable condition and abdominal CT was planned. On the CT images, findings were observed consistent with a $10 \times 16 \mathrm{~cm}$ hematoma within both rectus muscles and extending intra-abdominally from the right rectus muscle (Figure 2 and 3). As there was no history of trauma, the diagnosis was made of spontaneous rectus sheath hematoma. After consultation with the general surgeon, an operation was not considered as hemodynamics were not impaired. Supportive treatment was recommended and following resolution of the hematoma, the patient was discharged on the 35th day after admittance.

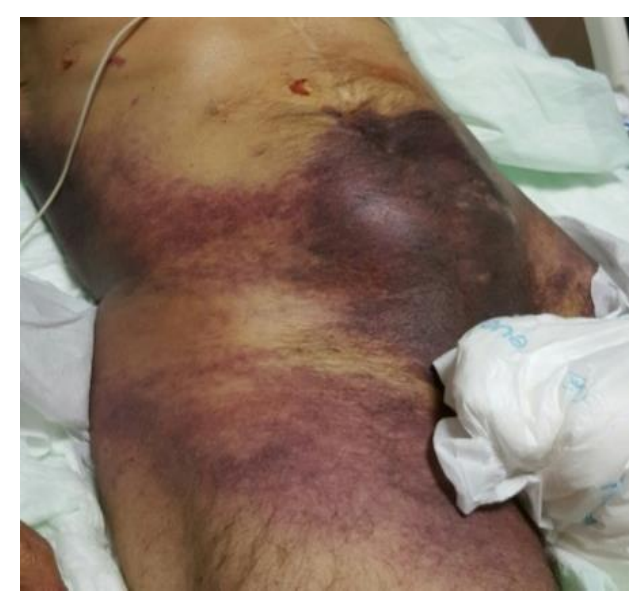

Figure 1: The image shows an extensive ecchymotic lesion.

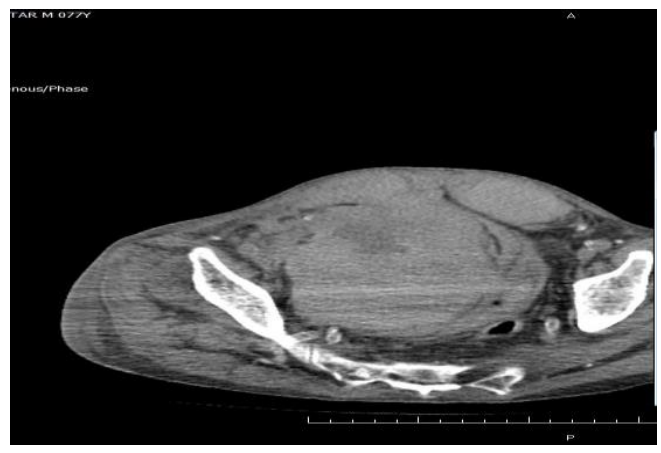

Figure 2: Sagittal view CT scan revealing hematoma within the rectus sheath and intrabdominal (arrow). 


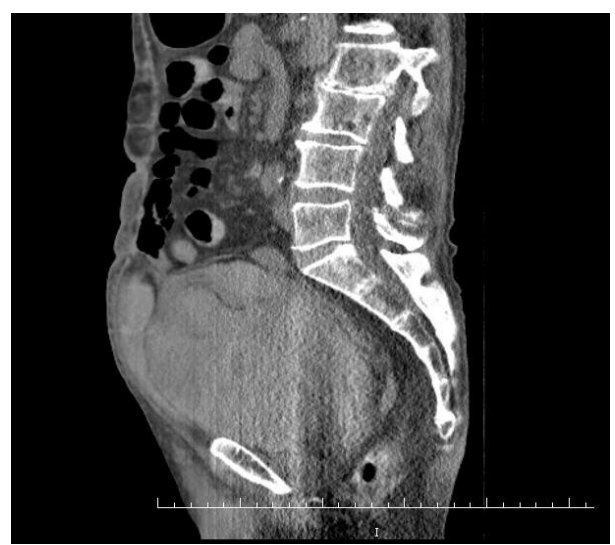

Figure 3: Horizontal view CT scan revealing hematoma within the rectus sheath and intrabdominal (arrow).

\section{Discussion}

Spontaneous rectus sheath hematoma is a complicated state which develops spontaneously within the rectus muscle, is generally unilateral, but may extend bilaterally and intra-abdominally depending on the severity. While surgery may be considered for patients with impaired hemodynamics or for those where hemostability cannot be provided with transfusion support, stable patients are followed up with supportive treatment. In the few cases in literature, it has generally been accompanied by anticoagulant use but not identified as autoimmune or vasculitis $[4,6]$. Although the most significant predisposing factor is anticoagulant treatment, it may be associated with various causes such as hematological diseases, trauma, drug injection, physical exercise, cough, sneezing, pregnancy and hypertension. According to the size and localisation, rectus sheath hematomas are separated into 3 types. This classification determines the physician's consultation requests and treatment options.

In Type 1 hematoma, bleeding is mild and contained within the muscle. In Type 2 hematoma, the hematoma is within the muscle but the bleeding is in the cavity between the fascia transversalis and the muscle. In Type 3 hematoma, the bleeding is severe, between the fascia transversalis and the muscle and anterior to the peritoneum and bladder. Patients are hospitalised and treated under close monitoring. Fluid resuscitation, and when required, blood and blood products transfusion may be administered. Surgical intervention may be necessary for hematomas that have increased in size or that cannot be brought under control. In the current case, the paravesical mass $10 \times 16 \mathrm{~cm}$ in size created the effect of a giant intra-abdominal hematoma both within and extending beyond the rectus sheath, causing a shift in placement of the intra-abdominal small and large intestines, but not blocking the exit of faeces. From the findings of the abdominal CT, this was classified as Type 3 rectus sheath hematoma. As defined in literature, erythrocyte support was provided with intermittent transfusion, as needed [3].

SLE onset at an older age has been reported in patients after the age of 50-65 years and this group comprises $2 \%$ $20 \%$ of lupus patients $[7,8]$. The reason for delayed diagnosis in the current case was considered to be that the patient was 78 years old, had a 5-10 year history of psychotic disorder, lived in a rural location, was uncared for and had not previously consulted a doctor because of the skin lesions. In the light of the clinical components and 
complications which were noticed in succession when the patient was hospitalised, a diagnosis of SLE was made in accordance with the ' 2015 ACR/SLICC revised criteria for the diagnosis of SLE'.

Although bleeding complications are rare in SLE patients in literature, they are encountered in the form of intraabdominal, intra-alveolar, soft tissue, or subdural bleeding [9]. To date, the mechanism of bleeding in SLE has not been fully clarified. A not inconsiderable number of cases have been reported where intra-abdominal hemorrhage/hematoma has been attributed to lupus [10, 12], but to the best of our knowledge there has been no reported case of rectus sheath hematoma for which lupus has been held responsible. As far as can be seen in the 2 cases reported to date $[13,14]$, the causes were said to be peritoneal dialysis and impaired coagulation function as a result of anticoagulant use respectively, and lupus was only mentioned as a comorbid disease.

Although anticoagulant treatment is the most important predisposing factor in the development of spontaneous rectus sheath hematoma, some questions come to mind about the reason for the current case hematoma. There was no history of anticoagulant use and with immediate low-molecular weight enoxiparin given as thromboembolism prophylaxis, within only 2 days the coagulation function test results were within the normal range, the Thjie disease activity of SLE remained high, and anti dsDNA and complement levels did not remain within the normal range, and therefore the formation of the hematoma was considered to have been due to SLE and the associated vascular involvement. However, it must be said that because of the APACHE II score of 17 of the patient and elevated GFR of $34.52 \mathrm{~mL} / \mathrm{min} / 1.73 \mathrm{~m}^{2}$, abdominal angio-CT couuld not be applied and thus the vascular structure could not be visualised.

\section{Conclusion}

In conclusion, the aim of this case report was to draw attention to how a standard case of pneumonia that could be encountered by all physicians became extraordinary, with the diagnosis of SLE, despite the advanced age of the patient, and the subsequent development of rectus sheath hematoma and that these two clinical states were considered to be related.

\section{References}

1. Ozen Ş. Sistemik lupus eritematosus' dan kaynaklanan kısa psikotik bozukluk: iki olgu nedeniyle. Klinik Psikofarmakoloji Bülteni 9 (1999): 159-166.

2. Brey RL, Holliday SL, Saklad AR, et al. Neuropsychiatric syndromes in lupus Prevalence using standardized definitions. Neurology 58 (2002): 1214-1220.

3. Berna JD, Garcia-Medina V, Guirao J, et al. Rectus sheath hematoma: diagnostic classification by CT. Abdominal imaging 21 (1996): 62-64.

4. Cherry WB, Mueller PS. Rectus sheath hematoma: review of 126 cases at a single institution. Medicine 85 (2006): 105-110. 
5. Costello J, Wright J. Rectus sheath haematoma: 'a diagnostic dilemma?'. Emergency Medicine Journal 22 (2005): 523-524.

6. Fitzgerald JE, Fitzgerald LA, Anderson FE, et al. The changing nature of rectus sheath haematoma: case series and literature review. International Journal of Surgery 7 (2009): 150-154.

7. Arnaud L, Mathian A, Boddaert J, et al. Late-onset systemic lupus erythematosus. Drugs and aging 29 (2012): 181-189.

8. Tomic-Lucic A, Petrovic R, Radak-Perovic M, Milovanovic D, et al. Late-onset systemic lupus erythematosus: clinical features, course, and prognosis. Clinical rheumatology 32 (2013): 1053-1058.

9. Espinosa G, Santos E, Cervera R, et al. Adrenal involvement in the antiphospholipid syndrome: clinical and immunologic characteristics of 86 patients. Medicine 82 (2003): 106-118.

10. Felipe-Silva A, de Campos FPF, dos Santos Martines JA. Fatal hemoperitoneum due to segmental arterial mediolysis. Autopsy and case reports 6 (2016): 7.

11. Ashouri JF, Davis JL, Farkas A, et al. A young woman with systemic lupus erythematosus and extensive mesenteric vasculitis involving small and medium vessels. Arthritis care and research 64 (2012): 19281933.

12. Yamaguchi M, Kumada K, Sugiyama H, et al. Hemoperitoneum Due to a Ruptured Gastroepiploic Artery Aneurysm in Systemic Lupus Erythematosus A Case Report and Literature Review. Journal of clinical gastroenterology 12 (1990): 344-346.

13. Balafa $\mathrm{O}$, Koundouris S, Mitsis M, et al. An unusual case of hemoperitoneum: spontaneous rectus sheath hematoma. Peritoneal Dialysis International 34 (2014): 134-135.

14. Toyonaga J, Tsuruya $\mathrm{K}$, Masutani $\mathrm{K}$, et al. Hemorrhagic shock and obstructive uropathy due to a large rectus sheath hematoma in a patient on anticoagulant therapy. Internal Medicine 48 (2009): 2119-2122.

Citation: Ayşe Şahin Tutak, Hüseyin Avni Fındıklı, Sefer Aslan, Esin Taştekin. Grade III Spontaneous Rectus Sheath Hematoma Concomitant to SLE. Archives of Clinical and Medical Case Reports 2 (2018): $162-167$.

This article is an open access article distributed under the terms and conditions of the Creative Commons Attribution (CC-BY) license 4.0 